\title{
17-Hydroxyprogesterone Measurement
}

National Cancer Institute

\section{Source}

National Cancer Institute. 17-Hydroxyprogesterone Measurement. NCI Thesaurus. Code C147370.

The determination of the amount of 17-hydroxyprogesterone present in a sample. 